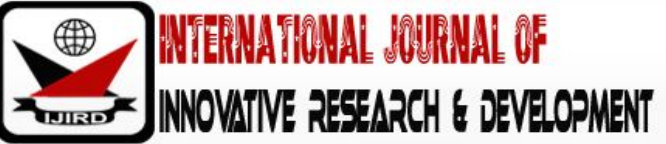

ISSN 2278 - 0211 (Online)

\section{Vowel Glides in Etsako: A Multilinear Phonological Approach}

\author{
Omoghie Ikphemhosimhe Aslem \\ Lecturer, Department of Arts, National Institute of Construction Technology, Nigeria \\ Odoemenam Temple Chibueze \\ Lecturer, Department of Arts, National Institute of Construction Technology, Nigeria
}

\begin{abstract}
:
Phonological investigations in Etsako over the years have paid more attention to the analysis of single segments without recourse to complex segments. Specifically, there are no studies that identify whether there are vowel glides in the language or not. In addition to this, studies have paid less concern to the activities of the rib cage in the production of segments in the language. This present study attempts to solve this twin problems and to ascertain if vowel glides occur in lexical formatives and in derivations. It was recognized that vowels which spread over two $\mathrm{V}$ positions and change from one quality to another constitute vowel glides. Using corpus from Uzairue, Ekperi and Uwepa, the study thus; present glides in Etsako using the multi-linear phonological framework with particular reference to CV phonology by Clements and Keyser (1983) (see also Kahn, 1976). On the whole, thirteen phonemic vowel glides where discovered to contrast with their single counterpart phonemic counterparts of which ten occur in lexical formatives while three occur in derivations.
\end{abstract}

Keywords: Vowel glides, resyllabification, multi-linear phonology, lexical formatives, derivations, CV phonology

\section{The Concept of Vowel Glides}

Vowels are often defined phonetically as segments which are produced without any obstruction as the air flows freely from the lungs through the vocal tract to the outside of the mouth. Vowels may differ in quality; which is informed by the activities of the articulators involved or differ in length which is determined by the amount of time the free flow of air lasted in the pronunciation. In other cases, vowels may differ from the two criteria mentioned above by moving from one quality to another (Donwa-Ifode, 2001). These differences may result to a meaning change depending on their distinctiveness in relation to individual languages.

The latter which is termed vowel glide occurs when there is a shift of vowel from one quality to another in such that it is pronounced in audibly longer period of time than that of a short vowel. Ugorji, (2015) opines that vowel glides occupy two (or more) successive vowel positions. They thus differ from short and full vowels in terms of the time-period allotted for their pronunciation and the length of pronunciation; and from vowel geminates since the latter is characterized by a single vowel quality at the systematic phonetic level of a lexical item. The two vowel typologies (germinates and glides) are however related in that both extend over two ' $\mathrm{V}$ ' positions and no hiatus may be associated with them during pronunciation (Ugorji; 2015) (see also, (Katamba, 1989).

In its simplest sense, vowel glide can be seen as a shift in quality from one single segment to another in a smooth succession. Some authors may refer to the concept as diphthong (see Roach, 1991, 1993, Nutsukpo, 1996). Roach for instance, while arguing for the presence of diphthongs (which he also called gliding vowels) in English insists that they are vowels with changing quality and thus glides from their original positions to another position which could be the centre of the mouth as in the sound / เə/ in 'hear', and at other times, the tongue may glide to the roof of the mouth as in /al/ in 'plight'. In a similar vein, Nutsukpo (1996) using data from English observes that the first vowel that make up the glide is longer in duration that the second one. Accordingly, [a e o] are longer in pronunciation than [l] in the words [bai] 'buy' [kerm] 'came' and [bor] 'boy' individually. Some English phonologists while engaging in minimal pair contrast between single vowels and diphthongs argue that diphthongs in English do not spread over two ' $\mathrm{V}$ ' positions but, are considered as a single phoneme even though it is a vowel with two qualities, thus; / hop/ and / həup/ can be said to contrast in identical environment. However, evidence from African languages (see Emenanjo, 1985, Ugorji, 2015) show that derivations can give room to glide thus making the vowels involved distinct phonemes at a particular point in time. Whichever concept is applied, it is noticed in this vowel typology that the length of the first segment in the sequence according to Nutsukpo, (1996) is usually longer than the second of a preceding vowel so that it spreads over two ' $\mathrm{V}$ ' positions resulting to lengthening when compared to its single segment counterpart. In most African languages, (Igbo, Bini, Berber, etc), vowel glides have proven to be distinctive and stands in complementary distribution with single phonetic segments (see Katamba, 1978, Ugorji, 2015.) This investigation thus follows the current trend as evident in the above-mentioned African 
languages. It therefore attests to the presence of vowel glides as prevalent in Etsako corpus in both lexical items and derivations.

Etsako language, also known as Yekhee (see Elugbe, 1986), is classified as a sub-group of the proto-North central Edoid of the Edoid language family. It is also a sub-group of the 'kwa' group of languages under the Niger - Kordofanian phylum (Greenberg, 1963). According to Bendor- Samuel (1989), Etsako is classified under the YEAI in the new Benue Congo Family. It incorporates thirteen dialects which are mutually intelligible across the geographical space within which the language is spoken. Speakers of Etsako are found in the sub-part of the present-day Edo-North (Afenmai) (Obaro, 1999). They are found in three Local Governments Areas: Etsako West, Etsako Central and Etsako East.

\subsection{Previous Works on Etsako Phonology}

In the early part of the twentieth century, Etsako was studied to some extent by Thomas (1914, and 1917) and Strub, (1917). Both authors referred to the language as Kukuruku; an informal name given to the division (The division is currently the present-day Edo North. It presently has six Local Government which are: Etsako West, Etsako East, Etsako Central, Akoko-Edo, Owan East and Owan West). Their aim was to draft an alphabetic system for the language. Accordingly, Thomas, (2014) provides twenty-three alphabetic letters (five vowels and twenty consonants) for the language. These include: A B D E F G H IJ K L MN O P R ST UV W Y Z

Thomas, (1917) however observes that these letters were not able to account for all the seven phonemic vowels in the language which include / a e $\varepsilon$ i $0 \mathrm{v} \mathrm{u} /$. He then extended the letters of the alphabet from 23 to twenty-five with the inclusion of: 'E Oo' for the vowels / $\varepsilon /$ and / $\mathrm{J} /$ respectively. Strub (1917) again observes that certain consonant sounds like $/ \int \mathrm{t} g \mathrm{gb} \mathrm{kph} g \mathrm{gh} \mathrm{x} \mathrm{y} /$ where not represented in the alphabet. He then introduces the diagraphs and trigraphs (SH, CH, GB, $\mathrm{KP}, \mathrm{KPH}, \mathrm{GBH}, \mathrm{KH}$ and $\mathrm{VH}$ respectively) to cater for these sounds in the language. These studies therefore introduce the sounds of the language and create an alphabet system for it. The major weakness of the studies however, is that the numerous languages prevalent in the division were treated as a single language, thus; are differ in terms of phonetic and phonemic resources. Evidences that show that these languages have the same phonemic features which are the basis for establishing orthography were not provided.

Laver, $(1967,1969)$ describes some aspects of the phonological system of Aviele dialect of Etsako. His focus was on identifying the phonemes of the dialect so as to create an orthographic system for the language. He identified twentyfive phonemic sounds in the language of which eighteen are consonants while seven are vowels. Accordingly, the

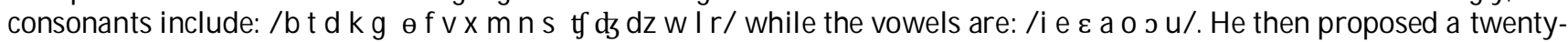
five-letter orthography which include: A B D E E F G I J K L MN O o R S T UV W Z, KH, VH, TH

One obvious weakness of this study however is the non-inclusiveness of other varieties of the language in the computation of the orthographic system. Uzairue, Avianwu, and Auchi dialects for instance has the phonemic sounds / $\mathrm{p} \mathrm{j}$ $\gamma /$. These sounds were not included in his sound inventory hence, not accounted for in the development of the orthography. The study thus negates the principle of socio-phonology which posits that contrastive socio-meaning should be a basis for characterizing the significant sounds, the candidate for the graphisation, in place of sound-meaning contrast (see Ugorji, 2010).

Using data from Ekperi dialect, Welmers, (1973) discusses the doubly articulated stops / kp/ / kph/ / gb/ and / gbh/. He observes that there is a phonemic contrast between these doubly articulated stops which is informed by the feature [ \pm suction]. He posits that the [+suction] sounds / $\mathrm{kp} \mathrm{gb/} \mathrm{are} \mathrm{produced} \mathrm{with} \mathrm{greater} \mathrm{articulatory} \mathrm{energy} \mathrm{when}$ compared with the [-suction] counterpart / $\mathrm{kph} \mathrm{gbh/.} \mathrm{He} \mathrm{therefore} \mathrm{concludes} \mathrm{that} \mathrm{/} \mathrm{kp/} \mathrm{and} \mathrm{/} \mathrm{gb/} \mathrm{are} \mathrm{tensed} \mathrm{consonants}$ while / kph/ and / gbh/ are lax consonants. The surface weakness of this investigation is the use of orthographic symbols to represent phonetic sounds. In addition, Welmers did not provide any instrumental evidence which is relevant in this type of investigation.

With data from Ekperi dialect, Elimelech, $(1973,1974)$ describes the tonal system of Etsako. According to him, two level tones (high and low) and two contour tones (rising and falling) are prevalent in the language. Other recent studies in the language include Omoghie, (2011) who describes the phonology of Uzairue dialect and Okpokpa, (2013) who studies the sound system of Ekperi dialect of the language. In line with Omoghie, (2011) and Okpokpa (2013), Etsako consists of 31

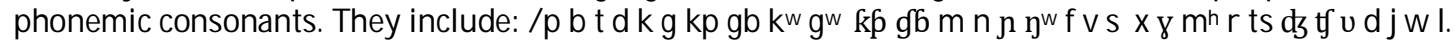

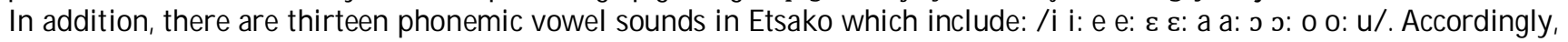
short vowels are attested to be inherent in the language while elongated vowels on the other hand are derived as a result of syllable deletion. When this deletion occurs, the preceding vowel elongates in order to make up for the lost syllable. In the following example, it is observed that the word / kà.lj̀ ' to count' underwent series of phonological process that result to and elongation of the vowel [a] and a deletion of the final syllable [lı̀].

- Underlying form:

- By C2 elision:

- By Coalescence

- By resyllabification:

/ kà.lo/ 'count'

[kà.æo]

[kà.à]

[kàà]

- Surface realization: / kà:/ 'count'

Omoghie, (2011) reports that other vowels like / i: e: $\varepsilon$ : ग: 0: / underwent similar phonological processes. He therefore concludes that whereas short vowels are inherent, long vowels are derived.

It is observed that the various studies above follow a classical approach in the analysis of the phonemes of the language and did not account for the present of glides in the language. More so, the studies were basically done using a particular dialect to make a generalization of how the entire language works. These few obvious facts necessitated this study. Attempt is therefore made here, to: 
- Identify and describe glides in Etsako;

- Observe if glides occur in lexical formatives and;

- Observe if glides occur in derivations

\subsection{Research Method}

This descriptive research was brought into light through oral interview and with the help of Uniben 200 hundred (200) word list of items. The word list consists of two hundred basic items which are believed to be present in all languages. The items include names of common animals, kitchen utensils, colour terms, angles and shapes, and other common words like action verbs. The word list has been attested to be able to provide adequate sounds that are prevalent in any language. Three dialects were chosen across the three Local Governments in which the language is spoken to represent the entirety of the language. Both oral interview and Uniben two hundred were thus used as instrument of data collections in these three dialects. Resultantly, Uzairue dialect was chosen from Etsako West, Uwepa from Etsako East and Ekperi from Etsako Central. Data from these three dialects where thus collated and analyzed using the multi-tiered phonological framework particularly the CV-phonology by Clement and Keyser, (1973).

\section{Theoretical Framework}

This section discusses CV phonology, phonological framework which proposes a multilinear representation of the syllable. The structure of the syllable is also discussed in the section in order to ascertain what constitutes it and how it can be uttered.

As earlier mentioned, this investigation is anchored on the theory of the syllable as perceived in the multi-linear phonological framework particularly the CV phonology by Clement and Keyser (1989) (see also Kahn, 1976 and Clement, 2000). This is justified owing to the fact that this theory shows specifically the structure which may be considered the universal requirement for the occurrence of vowel glides

The syllable is seen as sounds or group of sounds which can be pronounced in one breath (donwa-Ifode, 2001). On their part, Jakobson and Halle, (1968) opines that the syllable is a level of language structure which underlies the grouping of speech sounds and prosodies. The term as seen in Ugorji, (2015) refers to an element of phonological structure which consists in segments, organized in permissible intrinsic sonority which might constitute the basis for prosodic statements. Thus, the syllable is said to be the hub of phonology because, all investigations in the phonological parlance are better discussed when anchored on the syllable.

In Clement and Keyser, (1983) the syllable is said to consist of three tiers which are linked by association lines with each node having a vocabulary associated with it. Thus, at the apex is the syllable tier represented by ' $\sigma$ ' which is linked to the CV tier and there after linked to single phonetic matrices otherwise referred to as the segmental tier. See below.

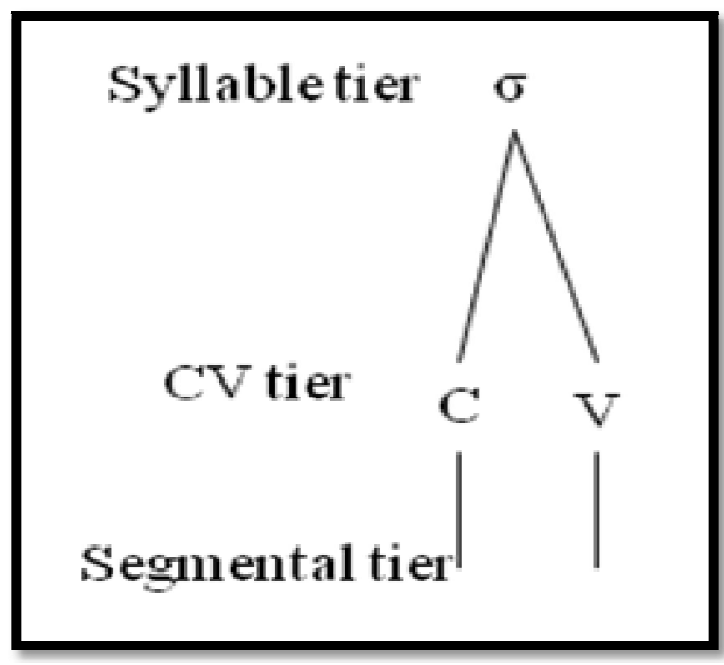

Figure 1: Three Tier Syllable

Accordingly, Goldsmith, 1976, 1990, McCarthy, (1981) posit that 'tier' are recognized as independent Plaines of representations. As seen above, there is a tier indicating a syllable constituent and another the CV tier while the last is the segmental. These are linked by association lines indicating how they may be co-articulated.

Since this theory evolved, there have been two main trends in the analysis of the syllable - the multi-tiered analysis and the hierarchical constituent structure. The multi-tiered representation on the one hand focuses on the link between the various tiers, how segments are co-articulated and how the syllables are fully syllabified at the lexical level of representation (Clement and Keyser, 1983, Clement, 2000). The hierarchical structure on the other hand focuses on defining positions of hedges of the syllable and the nucleus (see Katamba, 1989, Donwa-Ifode, 2001) thus; a syllable branches into an 'onset and a 'rhyme'; the rhyme incorporates the 'peak' (nucleus) and a 'coda' of which the only obligatory element of the syllable is the nucleus (vowels or vowel-like elements) as in the diagram below: 


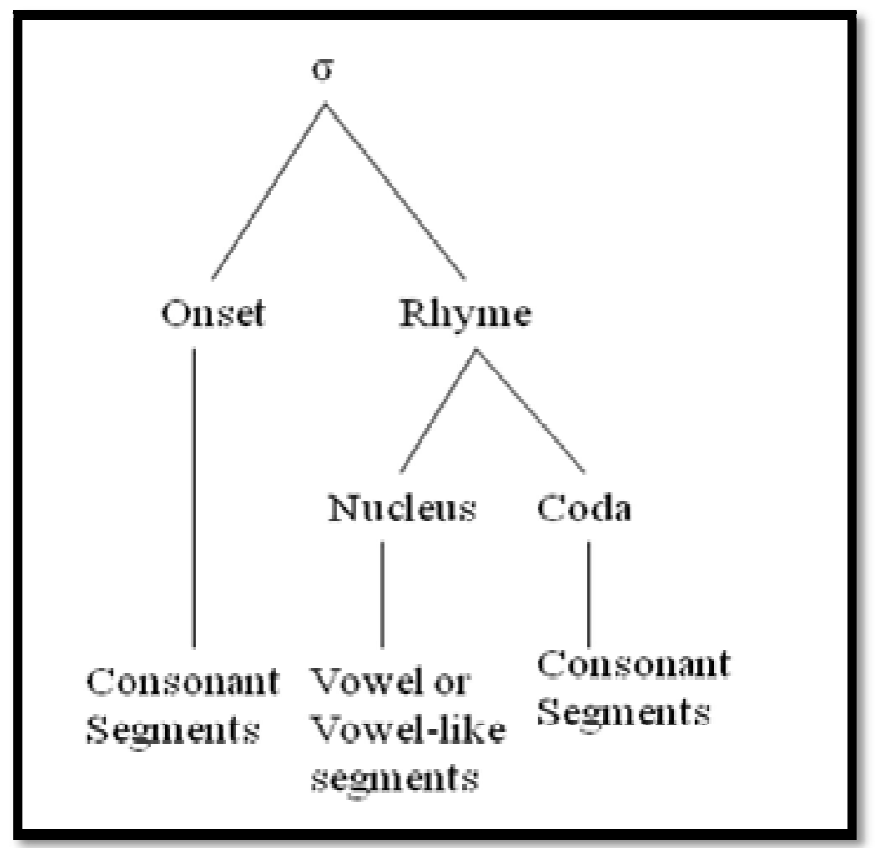

Figure 2: The Hierarchical Model of the Syllable

These two trends are incorporated in the analysis we are presenting here. Our emphasis however is on the nucleus since vowels occupy the nucleus position. In particular, research (see Katamba, 1989, Kenstowicz, 1994, Ugorji, 2015) proves that vowel glides are hosted by a branching nuclear node in syllable formation. This is in line with the universal obligation that the nucleus node be filled by syllabic units and that the number of syllables coincides with the number of syllabic units in a string (cf. Ugorji, 2015). Where more than one syllabic or vowel quality occurs, the nucleus node may branch, as in diphthongs or vowel glides, or a new syllable is formed. But when there is a single vowel quality, there will be no branching of the nucleus node.

This theory is crucial in defining syllable weight. As observed by Katamba, (1989), the major distinction drawn between syllable types found in languages has been between open syllables and closed syllables. Open syllables are said to be those without a coda. This syllable typology is observed in languages like Luganda, Edo, Urhobo etc. Closed syllables on the other hand are syllables that end with a coda as seen in languages like French, English etc. It has been observed that even in languages which allow closed syllables; there is often a clear preference for open syllables. A case of this sort is reported in French wherein, syllable final consonants suffer a considerable degree of attrition, where a rule deletes word final consonants in words like 'petit' / peti/ , 'comment' / komə/ consequently turning a supposed closed syllable to open syllable.

To this end, it has been suggested that rather than, the traditional approach to the classification of the syllable, syllable weight should be used as yardstick in the classification of the syllable (cf: Katamba, 1989). Thus, a syllable is light when it contains a non-branching rhyme and otherwise heavy when it contains a branching rhyme. Glides thus belongs to the latter category with germinates vowels and single segments occurring in a closed syllable.

\section{Vowel Glides in Lexical Formations}

This section presents data as evidence to show the presence of vowel glides in Etsako. It discusses the presence of vowel glides in lexical formatives and in derivations. Each of the vowel glide discussed in the section are presented in tables and the structure of such glides are analyzed using a syllable structure which incorporates the multi-tiered structure and the hierarchical structure. In what follows, we shall analyze these sounds using CV phonology one after the other.

\begin{tabular}{|c|c|c|c|}
\hline Vowel Glides & Words & $\begin{array}{c}\text { Phonemic } \\
\text { Transcription }\end{array}$ & Gloss \\
\hline / al/ & Aikpi & /áikpi// & 'anaconda' \\
\hline \multicolumn{4}{|c}{ Table $1:$ / a / as vowel glides }
\end{tabular}




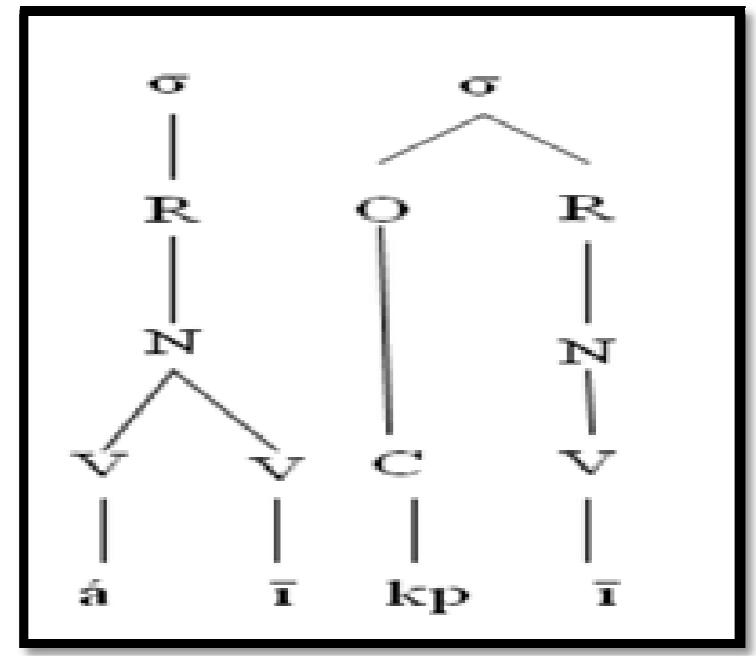

Figure 3: A Representation of / $\mathrm{A} l$ / Vowel Glides

Here, it is observed that / al/ is a glide sound in the language with two independent characteristics of phonemic features at word initial and thus; occupy a single nucleus position but spreads across two ' $\mathrm{V}$ ' positions.

\begin{tabular}{|c|c|c|c|}
\hline Vowel Glides & Words & $\begin{array}{c}\text { Phonemic } \\
\text { Transcription }\end{array}$ & Gloss \\
\hline$[\mathrm{Ol}]$ & Ikhoi & / ́́xòī/ & 'home' \\
\hline
\end{tabular}

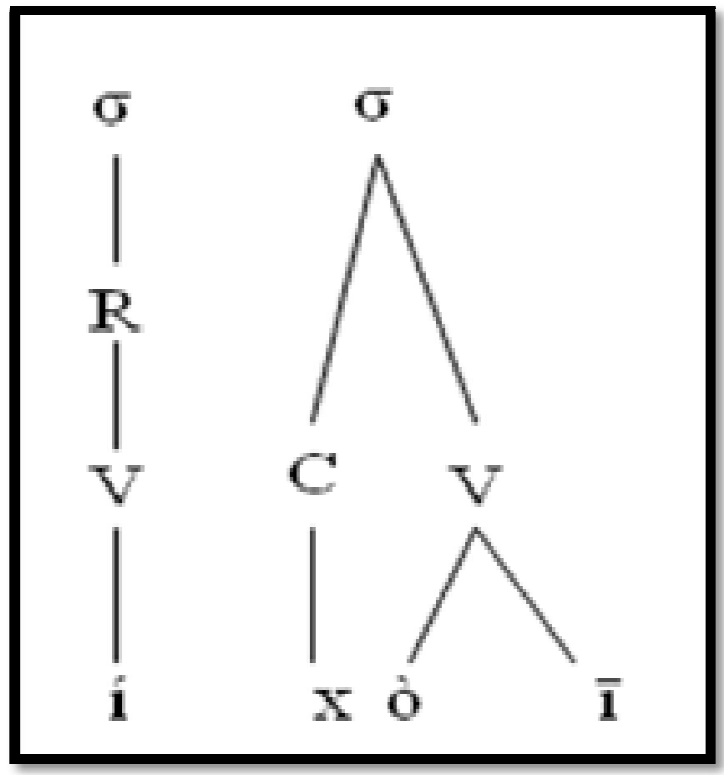

Figure 4: A Representation of / O / Vowel Glides

In this above example, it is seen that / ol/ works as a glide which spreads over to ' $\mathrm{V}$ ' positions in the above lexical formative. It is thus; seen as a glide in the language since it is characterized of two vowel qualities without any hiatus.

\begin{tabular}{|c|c|c|c|}
\hline $\begin{array}{c}\text { Vowel } \\
\text { Glides }\end{array}$ & Words & $\begin{array}{c}\text { Phonemic } \\
\text { Transcription }\end{array}$ & Gloss \\
\hline$[\mathrm{ul}]$ & Ului & / ūlùī/ & 'neck' \\
\hline \multicolumn{3}{|c|}{ Table 3: / ui/ as Vowel Glides }
\end{tabular}




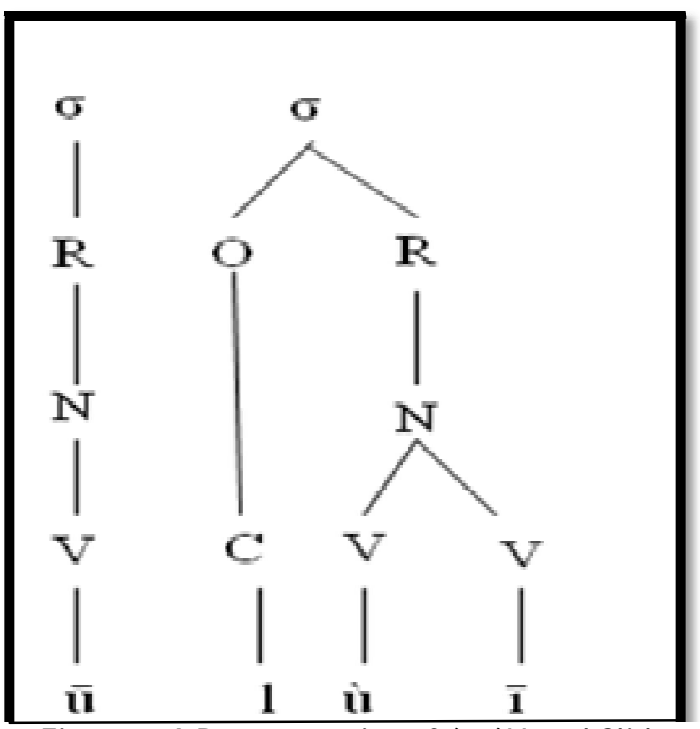

Figure 5: A Representation of / $\mathrm{u}$ / Vowel Glides

In the multilinear presentation above, it can be deduced that / ul/ constitute vowel glide in lexical formative as it meets the requirements as specified.

Other vowel glides which like the ones discussed above participate in this sort of formation in lexical formatives are thus; presented in the tables and represented in the figures that follow.

\begin{tabular}{|c|c|c|c|}
\hline Vowel Glides & Words & $\begin{array}{c}\text { Phonemic } \\
\text { Transcription }\end{array}$ & Gloss \\
\hline [ue] & Ukhue & / ūxùè/ & 'cup' \\
\hline
\end{tabular}

Table 4: / ue/ as Vowel Glides

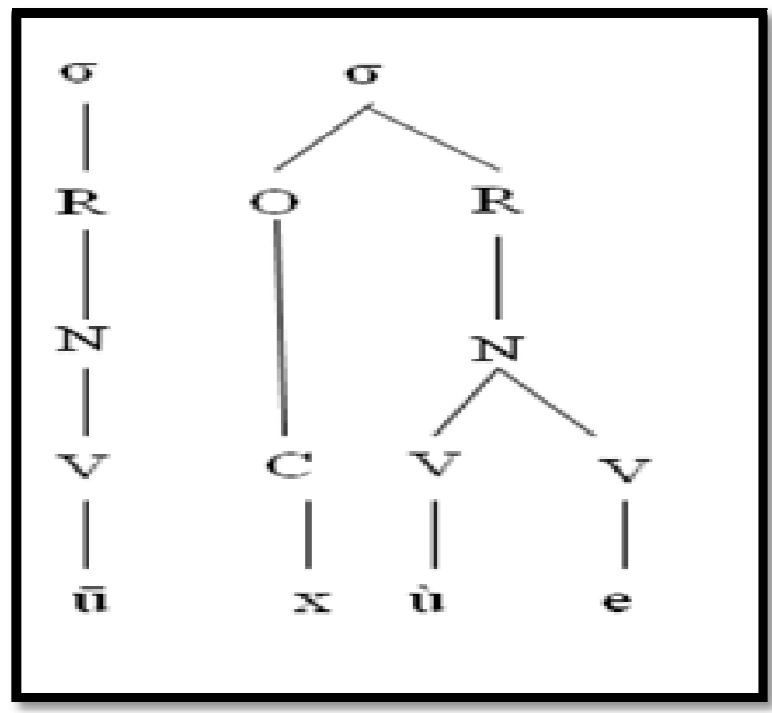

Figure 6: A Representation of / ue/ Vowel Glides

\begin{tabular}{|c|c|c|c|}
\hline $\begin{array}{c}\text { Vowel } \\
\text { Glides }\end{array}$ & Words & $\begin{array}{c}\text { Phonemic } \\
\text { Transcription }\end{array}$ & Gloss \\
\hline [ua] & Arua & $\begin{array}{c}\text { /àrùà/ } \\
\text { / áyùà/ }\end{array}$ & $\begin{array}{c}\text { 'festival' } \\
\text { 'taboo' }\end{array}$ \\
\hline
\end{tabular}

Table 5: / ua/ as Vowel Glides 


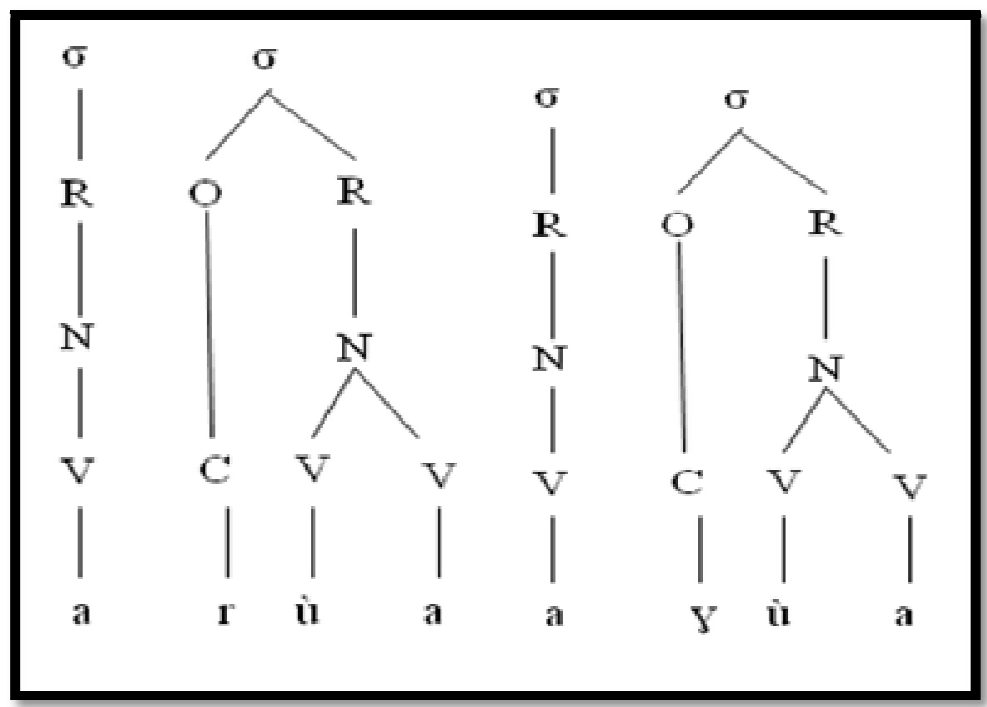

Figure 7: A Representation of / ua/ Vowel Glides

\begin{tabular}{|c|c|c|c|}
\hline $\begin{array}{l}\text { Vowel } \\
\text { Glides }\end{array}$ & Words & $\begin{array}{c}\text { Phonemic } \\
\text { Transcription }\end{array}$ & Gloss \\
\hline \multirow[t]{6}{*}[\imath\varepsilon]{} & ishiẹ & / ífił̀) & 'sponge' \\
\hline & shiẹ & / fì̀)/ & 'to be short' \\
\hline & kiẹ & / kìz̀/ & 'to lament' \\
\hline & viẹ & / vì̀े/ & 'cry' \\
\hline & giẹ & / gì̀े/ & 'laugh' \\
\hline & miẹ & / mì̀̀/ & 'to see' \\
\hline
\end{tabular}

Table 6: / $\iota$ / as Vowel Glides

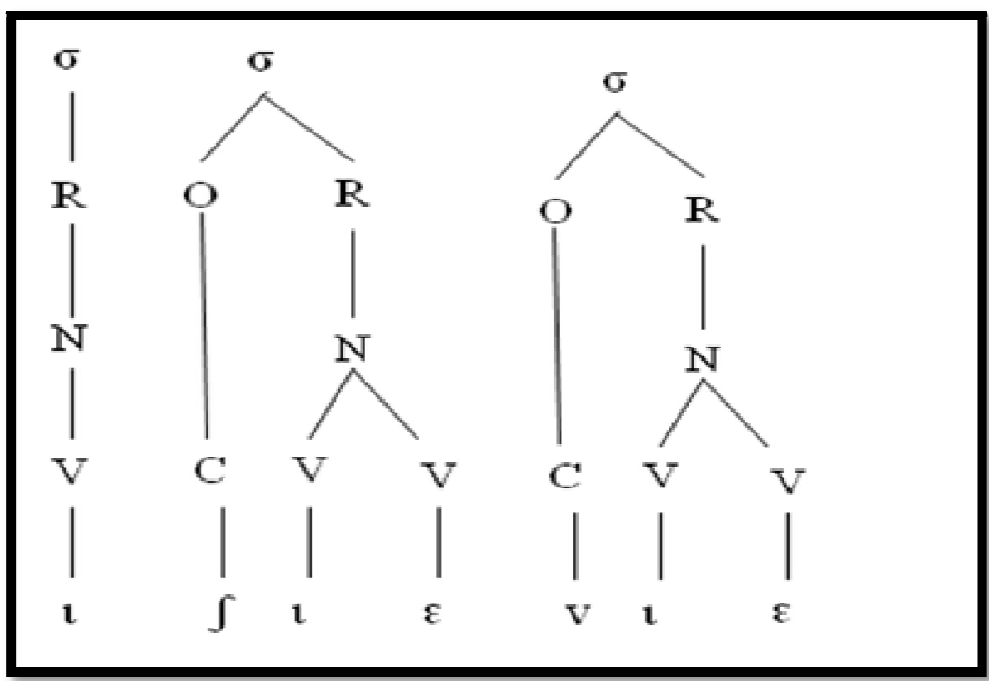

Figure 8: A Representation of / $\llcorner\varepsilon /$ Vowel Glides

\begin{tabular}{|c|c|c|c|}
\hline $\begin{array}{c}\text { Vowel } \\
\text { Glides }\end{array}$ & Words & $\begin{array}{c}\text { Phonemic } \\
\text { Transcription }\end{array}$ & Gloss \\
\hline [ıe] & Oghie & / òyìe/ \\
/ miè/ & 'king' & 'to receive' \\
\hline
\end{tabular}

Table 7: / $\mathrm{e} /$ as Vowel Glides 


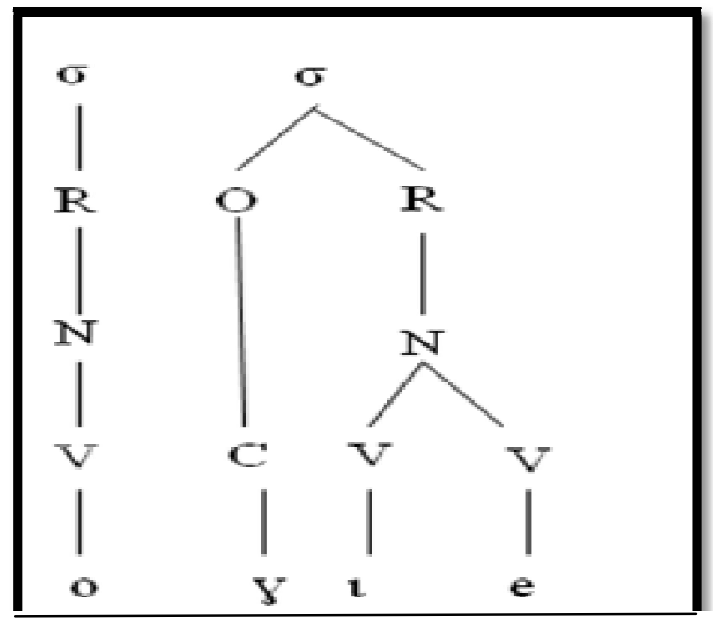

Figure 9: A Representation of / $\iota$ e/ Vowel Glides

\begin{tabular}{|c|c|c|c|}
\hline Vowel Glides & Words & $\begin{array}{c}\text { Phonemic } \\
\text { Transcription }\end{array}$ & Gloss \\
\hline$[ı]$ & Okhio & / óxì̀/ & 'devil' \\
\hline
\end{tabular}

Table 8: / ı0/ as Vowel Glides

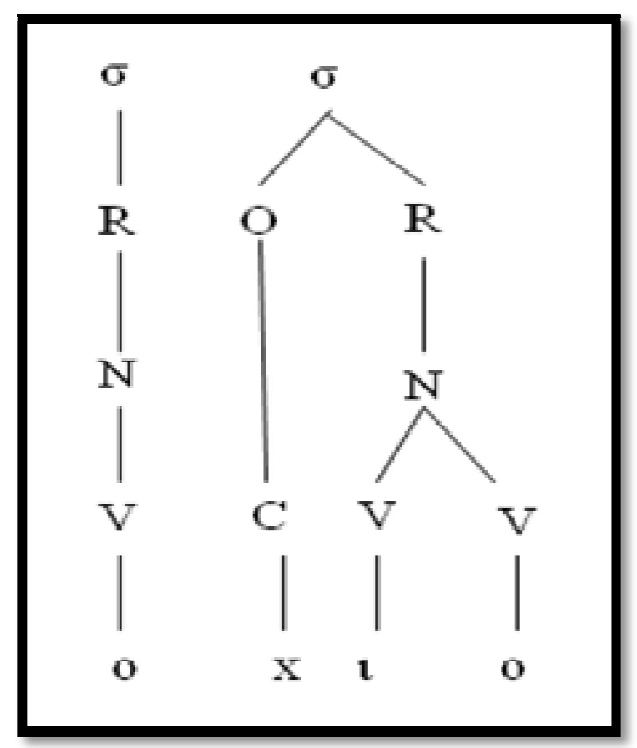

Figure 10: A Representation of / $\iota$ / Vowel Glides

\begin{tabular}{|c|c|c|c|}
\hline Vowel Glides & Words & $\begin{array}{c}\text { Phonemic } \\
\text { Transcription }\end{array}$ & Gloss \\
\hline$[\iota]$ & ufiọ & / úfì̀ & 'light' \\
\hline
\end{tabular}

Table 9: / $\iota /$ as Vowel Glides 


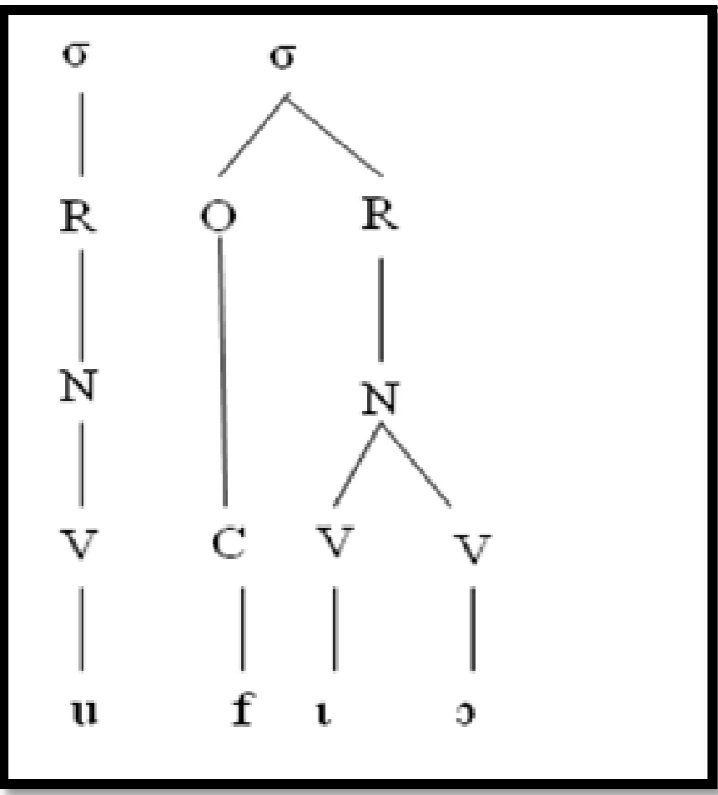

Figure 11: A Representation of / ı/ Vowel Glides

\begin{tabular}{|c|c|c|c|}
\hline Vowel Glides & Words & $\begin{array}{c}\text { Phonemic } \\
\text { Transcription }\end{array}$ & Gloss \\
\hline$[\mathrm{ta}]$ & Úlìa & / úlià)/ & 'vain' \\
& Ákhìa & 'áxià/ & 'tsetse fly' \\
\hline
\end{tabular}

Table 10: / $\mathrm{ra}$ / as Vowel Glides

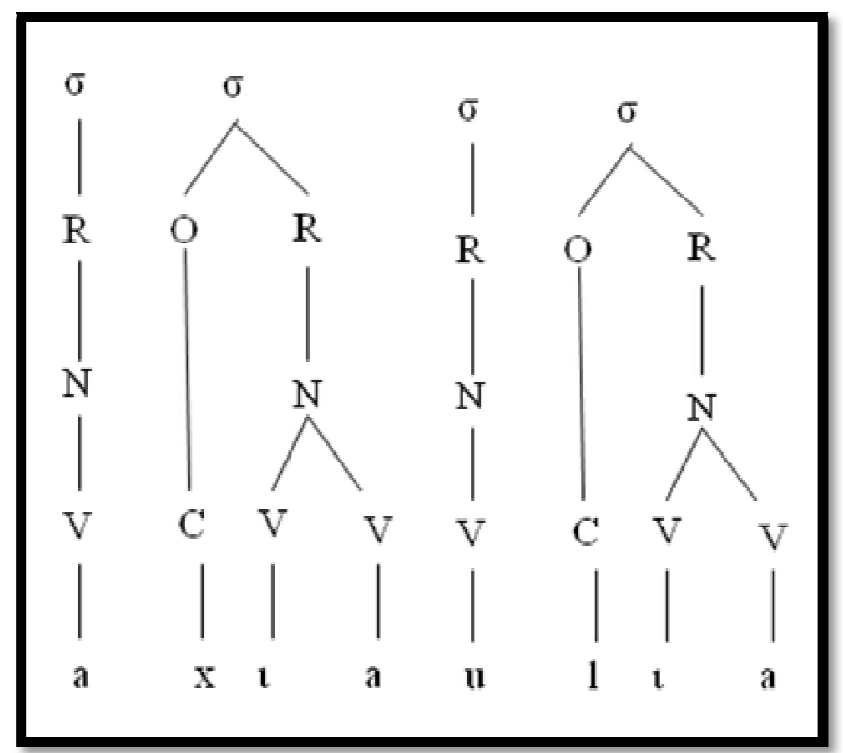

Figure 12: A Representation of / la/ Vowel Glides

\subsection{Vowel Glides in Derivatives}

Beside the glide typology discussed above, this research also identifies vowel glides which are formed as a result of derivations that results from a deletion of an approximant (lateral $/ \mathrm{l} /$ or palatal approximant $/ \mathrm{j} /$ ) which occur intervocalically. At other times, it may be as a result of word formation through the coming together of two lexical items. Data showing these are presented below:

\begin{tabular}{|c|c|c|c|}
\hline Vowel Glides & Words & $\begin{array}{c}\text { Phonemic } \\
\text { Transcription }\end{array}$ & Gloss \\
\hline$[$ oa] & Punoa & /pùnòà/ & 'quench' \\
\hline
\end{tabular}

Table 11: / oa/ as Vowel Glide 


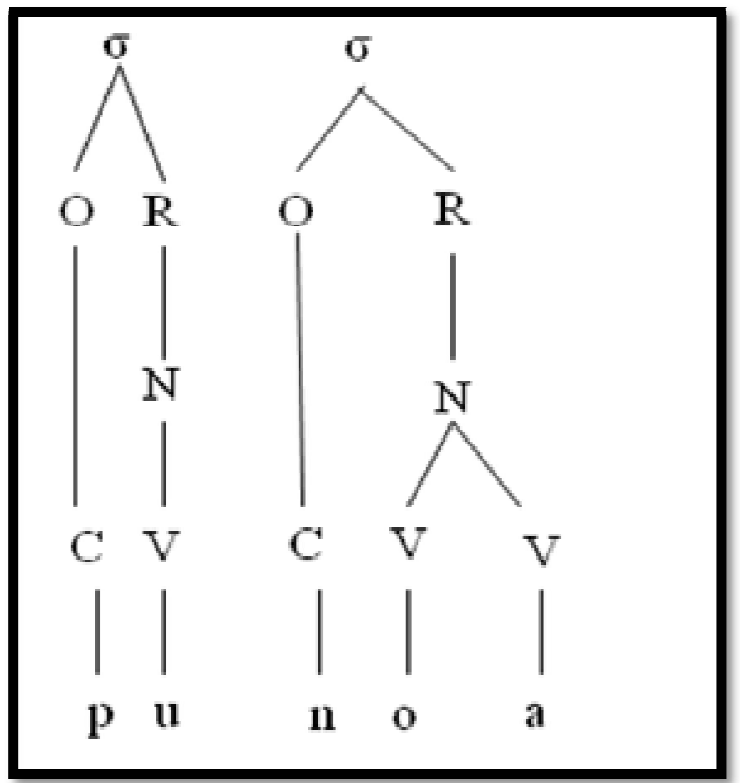

Figure 13: A Representation of / Oa/ Vowel Glides

This derivation was got from the / puno/ 'switch off' and the morpheme / ja/ which relates to complete. In derivation, there is a total deletion of the palatal approximant and the resulting sequence is / punoa/ .

Another process of vowel glide formation is the deletion of the lateral approximant / $1 /$ that occurs intervocalically. Thus; the word undergoes a process of resyllabification, and a glide is formed. See examples in tables 13 and 14 and in figure 18 and 19.

\begin{tabular}{|c|c|c|}
\hline Vowel Glides & Words & Gloss \\
\hline$[\mathrm{ae}]$ & Emae & 'food' \\
\hline
\end{tabular}

Table 12: / ae/ as Vowel Glide

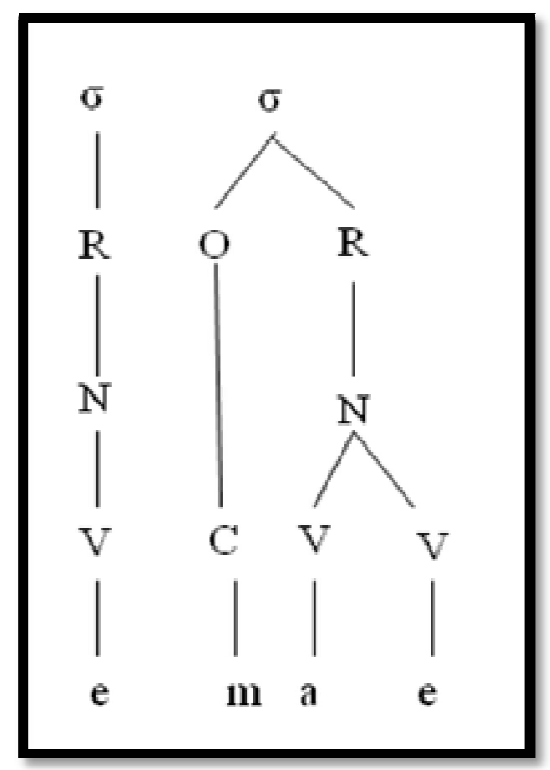

Figure 14: A Representation of / ae/ Vowel Glides

\begin{tabular}{|c|c|c|c|}
\hline Vowel Glides & Words & $\begin{array}{c}\text { Phonemic } \\
\text { Transcription }\end{array}$ & Gloss \\
\hline$[a \varepsilon]$ & ugwaè & / ùgwà̀े/ & 'living room' \\
\hline
\end{tabular}

Table 13: / ac/ as Vowel Glide 


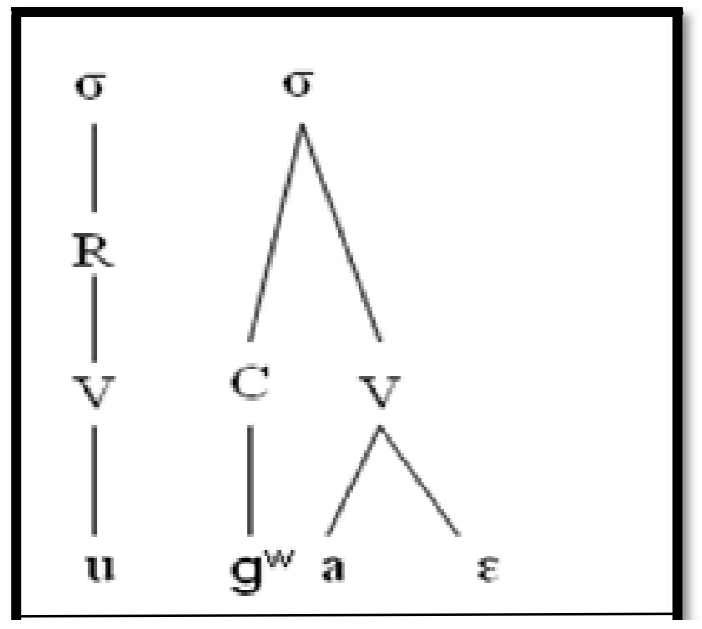

Figure 15: A Representation Of / A $\varepsilon$ / Vowel Glides

\subsection{Discussion}

The crux of this study is to ascertain if vowel glides occur in lexical items and in derivations in Etsako and also to determine the requirement for a branching nucleus between consecutive vowels with different qualities in the language. The data above thus presented evidences of vowel glides in lexical formatives and derivations.

Evidences from the data presented above show that there is a clear evidence of ten (10) vowel glide in lexical formatives while four (4) occur in derivations.

At one extreme as shown in table 1-3, we observed that vowel glides can end a close front vowel of the sort / al, ou, $\mathrm{ul} /$. at the other extreme, it is observed in tables 5, 11, 12 and 13 that vowel glide can end with an open vowel. Beside these two patterns mentioned, data also reveal that vowel glide can end either a close mid or open mid vowel. Consequently, there is no restriction on the vowel in the language to participate in vowel glide.

Evidences from the research also identify vowel glides which are formed as a result of derivations that results from a deletion of an approximant (lateral approximant / l/ as in tables 13 and 14 or palatal approximant /j/ as in table 11) which occur intervocalically. At other times, it may be as a result of word formation through the coming together of two lexical items as seen in table 12.

The above data thus; demonstrate the occurrence of a branching nucleus in the syllable formations; where $\mathrm{V}_{1}$ is not equivalent to $V_{2}$ which is the bed rock of vowel glide system. Phonemic contrast could also be drawn between the single segments and vowel glides as in ghie 'send' and ghi 'build'. Other examples include:

- khì 'walk'

- khì 'tighten'

- kàì 'count'

- kà 'buy (drink)'

- ùlù 'light'

- ului 'neck'

- wùè 'garnish'

- wù 'grind (cassava)'

- khì 'sell'

- khì 'tighten'

\section{Summary and Conclusion}

The crux of the study is given to the investigation of vowel glides in lexical formatives and derivations in Etsako. Data for the study were drawn from three dialects of the language; Uzairue, Ekperi and Uwepa. Collection of these data were direct soliciting from informant with Uniben two-hundred-word list of items. Results were analyzed using the multilinear phonological framework with the incorporation of Hierarchical model and CV phonological model. The research thus shows that in addition to the single vowel segments already recognized in the language, there are thirteen vowel glides. Of these, ten occur in lexical formatives while the other three are formed through derivations. The language thus, corresponds with majority of languages (Igbo, Edo, Esan, Yoruba etc) in the kwa group which have been attested to be characterized by vowel glides.

\section{References}

i. Clerk M.M. 1990. The Tonal System of Igbo. Dordrecht: Foris Publications.

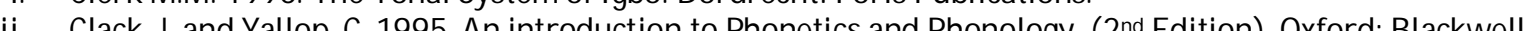


iii. Clements, G.N. 2000. "Phonology" in African Languages: An Introduction. Heine

iv. Clements, G.N. and Keyser, S.J. 1983. CV Phonology: A Generative Theory of the Syllable. Cambridge: MIT Press.

v. Donwa-Ifode, S. 2001. Basic Phonetics. Port Harcourt: University of Port Harcourt Press.

vi. Dudusola, D, 2010. Aspects of the Phonology of Itsekiri. An Unpublished B.A. Project Submitted to the University of Port Harcourt.

vii. Elimelech, Baruch, 1978. A Tonal Grammar of Etsako. Los Angeles: University of California Press

viii. Elugbe, B.O. 1986. Comparative Edoid. Port Harcourt: University of Port Harcourt Press.

ix. Emenanjo, E.N. 1987. Elements of Modern Igbo Grammar. Ibadan: Oxford University Press.

x. Goldsmith, J. 1976. "An Overview of Autosegmental Phonology" in Linguistics Analysis. 2,1:23-63

xi. Goldsmith, J. 1990. Autosegmental and Metrical Phonology. U.K. Basil Blackwell Ltd.

xii. Green, M.M. and Igwe, G.E. 1963. A Descriptive Grammar of Igbo. Berlin: Akademic Verlag.

xiii. Greenberg, J.H. 1963. Studies in African Linguistic Classification. New Haven: Compass Publishing Company.

xiv. Jakobson, R. and Halle, M. 1968. "Phonology in Relation to Phonetics" in Manual of Phonetics, Malmberg, B. (Ed.) Amsterdam: North-Holland Publishing Company pp.411.

xv. Kahn, D. 1980. Syllable-Based Generalizations in English Phonology. New York: Garland Publication

xvi. Katamba, F. 1989. An Introduction to Phonology, London: Longman

xvii. Kenstowicz, M. 1994. Phonology in Generative Grammar. Cambridge MA: Blackwell.

xviii. Ladefoged, P. 1964. A Phonetic Study of West African Languages. Cambridge: Cambridge University Press.

xix. Laver, J.D.M. 1969. "Etsako Aywele dialect" in Twelve Nigerian Languages, Dustan, Elizabeth (Ed.) London: Longman, Green and Co. Ltd. 47-57.

xx. Ndimele, O-M. 1985. Aspects of the Phonology of Echie. An Unpublished B.A. Project Submitted to the University of Port Harcourt.

xxi. Nutsukpo, G.A. 1996. Phonetics, Phonology and Spoken English. Port Harcourt: Eimhai Press.

xxii. Obaro, I. 1999. Groundworks on Nigerian History. Ibadan: Oluseyi Press.

xxiii. Okpokpa, P. 2013. The Phonology of Ekpei Dialect of Etsako. B.A. Project Submitted to the University of Benin.

xxiv. Omoghie, I.A. 2011. A Phonology of Uzairue Dialect of Etsako. B.A. Project Submitted to the University of Port Harcourt.

xxv. Roach, P. 1991. English Phonetics and Phonology: A Practical Course. Cambridge: Cambridge University Press.

xxvi. Sloat C., Sharon, H.T. and James E.H. 1978. Introduction to Phonology. Eaglewood Cliffs: Prentice Hall

xxvii. Thomas N.W. 1914. Edo-Speaking People of Nigeria. London: Harrison and Sons, reprinted in 1969, Negro University Press.

xxviii. Udo, L.I.I. 2003. Introduction to Phonemic Analysis, Lagos: Concept Publications Ltd.

xxix. Ugorji, C.U.C. 2002. "The Structure of Syllable in Mbieri: A Multilinear Approach" in Kiabara 8, 2: 89-99

xxx. Ugorji, C.U.C. 2010. "A Sociophonological Model for Orthographies in the New World Democracy in Modern Journal of Applied Linguistics 1, 360-381.

xxxi. Ugorji, C.U.C. 2015. "Vowel Glides and Germinates in Igbo: Why not?" In Journal of Linguistics Studies, Benin City: Mindex Press Ltd.

xxxii. Uwuma, D.U. 2010. Aspects of the Phonology of Ekpeye. An Unpublished M.A. Seminar Submitted to the University of Port Harcourt.

xxxiii. Welmers, W.E. 1973. African Language Structures. Berkeley: University of California Press

xxxiv. Yul-Ifode, Shirley. 1999. A Course in Phonology. Port Harcourt: University of Port Harcourt Press. 